Ihr saizsaures Salz ist gut krystallisirbar, aber sehr zerfliefslich. Mit Platinchlorid giebt es einen flockigen, nicht krystallinisch werdenden Niederschlag, der sich beim Erhitzen der Flüssigkeit zersetzt. Mit Quecksilberchlorid bildet es eine milchige Trübung, die durch ölförmige Tröpfchen bewirkt wird. - Das Hygrin ist nicht giftig; einige Tropfen einem Kaninchen eingegeben waren ohne sichtbare Wirkung.

Als Cocablätter mit Kalkmilch oder mit Natronlauge destillirt wurden, ging eine alkalisch reagirende, nach Ammoniak und zugleich nach Trimethylamin riechende Flüssigkeit über. Nach der Sättigung mit Salzsäure und nach dem Abdampfen hinterliefs sie ein Salz, welches im Wesentlichen aus Salmiak bestand, welches aber deutlich noch Spuren von einer anderen Base enthielt, von der es ungewifs blieb, ob sie Hygrin war.

$W$.

\title{
Wirkung von nascirendem Wasserstoff auf Zimmtsäure;
}

von Erlenmeyer und Alexejeff.

(Briefliche Mittheilung von Dr. Erlenmeyer.)

Die sehr merkwürdige Art der künstlichen Zusammensetzung der Zimmtsäure aus Acetyl und Benzoyl, welche B ertagnini*) kennen gelehrt hat, liefs es als möglich erscheinen, dieselbe an ihrer Zusammenfügungsstelle auch wieder zu zerreifsen, wenn man den beiden Bruchstücken Gelegenheit böte, sich jederseits mit Wasserstoff zu verbinden. Ich stellte in der Absicht, aus der Zimmtsäure durch nascirenden Wasserstoff Acetyl- und Benzoylaldehyd zu erzeugen, mit Herrn A lexejeff aus Petersburg einige Versuche an. Wir brachten mit einer Zimmtsäurelösung, die noch viel ungelöste Zimmt-

*) Diese Annalen C, 125. 
säure enthielt, Natriumamalgam in grofsem Ueberschufs zusammen, da es ja immerhin denkbar war, dafs der Wasserstoff nicht spaltend, sondern sich verbindend eintrete. In letzterem Falle konnte eine so grofse Menge aufgenommen werden, dafs der Kohlenstoff vollständig gesättigt und die Zimmtsäure so in Pelargonsäure übergeführt wurdc.

Während der Reaction war kein besonderer Geruch bemerkbar. Nach Beendigung derselben schied sich auf Zusatz von überschüssiger Salzsäure eine Substanz in farblosen klaren Tropfen, die beim Schütteln erstarrten, am Boden des Gefäfses ab. Wir dachten, es sei das Homologe zu einer der Toluylsäuren. Mehrere übereinstimmende Elementaranalysen der gereinigten Substanz selbst, sowie des Silbersalzes und Bestimmungen des Silbers in letzterem führten zu der Annahme, dafs der erhaltenen Säure die Zusammensetzung $\mathrm{G}_{i 9} \mathrm{H}_{12} \Theta_{2}$ zukommt.

Aber trotzdem, dafs die Analysen sehr genau mit dieser Zusammensetzung stimmende Resultate gegeben haben, wage ich doch nicht, die obige Formel für den unumstöfslich richtigen Ausdruck derselben zu erklären, weil die Unterschiede in den Verhältnissen der Bestandtheile einer der Toluylsäure homologen und der unserer Formel entsprechenden Säure zu gering sind, um auf die blofse Analyse hin über die wahre Stellung unserer Substanz zu entscheiden.

Meines Wissens ist bis jetzt ein einziges Glied aus der Reihe, welcher die Säure $\mathrm{G}_{9} \mathrm{H}_{12} \theta_{2}$ angehören müfste, bekannt. Es ist die von Personne*) im Jahre 1856 aus dem Terpentinölhydrat dargestellte Terebentilsäure $G_{8} \mathrm{H}_{10} \Theta_{2}$, welche nur unvollkommen untersucht ist. Unsere Säure hat auch, wie Personne von der Terebentilsäure sagt, einen Bocksgeruch, aber ihr Schmelzpunkt liegt nach vorläufiger Bestimmung ungefähr bei $45^{\circ}$, während derjenige der Terebentilsäure von Personne bei $90^{\circ}$, gefunden wurde. Diese Abweichung wäre der Annahme einer Homologie nicht geradezu widersprechend, aber ehe wir uns bestimmt dafür erklären, halten wir es für unumgänglich nöthig, die Terebentilsäure selbst genauer zu untersuchen und mit unserer Säure zu vergleichen.

*) Diese Annalen C, 253.

Ausgegeben den 6. März 1862. 